\begin{tabular}{|l|l|l|l|l|l|l|}
\hline InterteXto & Uberaba & UFTM & v. 1 & p. 227-241 & 2008 - jan. / jun. & ISSN 1981-0601 \\
\hline
\end{tabular}

\title{
A CONSTRUÇÃO DE SENTIDOS DO TEXTO NOS PROGRAMAS DE BATE- PAPO DA INTERNET
}

\section{THE CONSTRUCTION OF SENSE OF THE TEXT IN PROGRAMS OF CHATS AT INTERNET}

Kelly Christine Lisboa Diniz ${ }^{1}$

\begin{abstract}
Resumo
A transformação da sociedade e de seus valores ocasionou igual mudança no comportamento das formas de comunicação entre seus membros. Conforme descreve Maingueneau (2002, p.72), "muitas mutações sociais se manifestam por meio de um simples deslocamento midiológico (relativo ao mídium)". A Internet proporcionou essa mudança nas relações pessoais. Com o advento da globalização as relações mundiais se estreitaram e a necessidade das pessoas se manterem informadas em tempo real se fez fundamental. Em meio a este aglomerado de tecnologia é que surgiram os batepapos da Internet, que encurtam distâncias, além de proporcionarem uma interação entre usuários que buscam estes serviços por motivos dos mais diversos. Para lidar com essas expressões orais e escritas que se propõe uma análise a fim de demonstrar a coerência e o sentido nesse meio textual.
\end{abstract}

Palavras-chave: Internet; bate-papo; oralidade; escrita.

\begin{abstract}
The transformation of the society and its values caused equal change in the behavior of the forms of communication between its members. As it describes Maingueneau (2002, p.72), "many social mutations if they reveal by means of a simple midiológico displacement (relative to mídium)". The InterNet provided this change in the personal relations. With the advent of the globalization, the world-wide relations got narrowed and the necessity of people to keep informed in real time is essential. In way to this accumulation of technology the chats had appeared at InterNet, that shorten distances, Besides to provide an interaction between users who search these services for many reasons. To deal with these verbal expressions and writings, considers an analysis to demonstrate the coherence and the direction in this literal way.
\end{abstract}

KEYWORDS: chat; orality; writing.

Uma das formas mais utilizadas de bate-papos virtuais atualmente são as mensagens instantâneas, ou os programas de troca de mensagens. Este gênero bate-papo agendado ou agendável começou com o ICQ (I seek you ou Eu procuro você) e o IRC (Internet Relay Chat ou retransmissão de conversas

${ }^{1}$ UFES. kcldiniz@hotmail.com 
pela Internet) (MARCUSCHI, 2004; p.33-34), e chegou até ao MSN Messenger (chat room) da Microsoft que ganhou maior popularidade hoje no Brasil.

Segundo Osvaldo Barbosa Oliveira, diretor do MSN para o Brasil e América Latina, o último relatório datado de janeiro de 2004 pelo IBOPE/ NetRatings registra 7,6 milhões de usuários só no Brasil, ao passo que o ICQ perdeu algum espaço por ser um programa, até a última vez consultado, todo em língua inglesa, além de ter perdido, o que a mesma pesquisa constata, liderança e popularidade entre os usuários.

Essas mensagens virtuais, diferentemente das salas de bate-papos do mesmo gênero, podem se dar por relações interpessoais, ou seja, entre dois usuários reservadamente, ou ainda, pelo convite para que várias pessoas da lista pessoal de contatos do usuário participem do ciclo de conversa virtual, como conversas face a face, com a diferença de que essas conversas virtuais não possuem a presença dos interlocutores, elas são escritas, geralmente, e também não contam com atos que são próprios da fala, como gestos, articulação, ambiente.

As propriedades da fala face a face por meio do ambiente virtual se misturam em um misto de cultura, comunicação, interação e informação, por meio de elementos simuladores das interações cotidianas, como: caixa de fotografia ou de imagem; som, como o áudio, música e linguagem através de uma integração de recursos semiológicos conhecidos como emoticons (carinhas que transmitem estados de espírito) e os winks que fazem o papel da representação do estado de espírito da pessoa, bem como algumas atitudes que possivelmente tomaria o usuário em uma interação face a face.

Todas essas características aliadas a outras de caráter social, como o aumento da violência, principalmente nas grandes cidades, têm feito com que, sobretudo a juventude, procure cada vez mais os serviços disponíveis na Internet, inclusive para as relações pessoais. Ainda, segundo o lbope/ NetRatings, "as novas gerações estão nascendo Digitais, para eles a Internet é mais Real que o mundo real", por isso classificam os jovens atuais como: 
fragmentados; dispersos, por não conseguirem ter foco em uma tarefa só; e acostumados a ter tudo de forma "free", por estarem crescendo em mundo multifacetado.

Significa dizer que essa linguagem mais informal; ou totalmente independente de um sistema convencional de uso da escrita, se valendo até mesmo de abreviaturas pouco ou algumas vezes até desconhecidas, constitui um emaranhado solto de palavras sem sentido ou até mesmo inaceitáveis do ponto de vista textual?

\section{ORALIDADE E ESCRITA}

Durante muito tempo, a tradição oral estabeleceu as relações sóciocomunicativas, os povos transmitiam suas crenças e cultura por meio de ensinamentos de geração para a geração. Com a implantação da escrita na sociedade contemporânea, a escrita passa a ter um status de superioridade com relação à oralidade por mitos criados em torno da escrita de que ela seria o passaporte para a civilização e para o conhecimento, como defendiam alguns estudiosos como Olson (1997; p.30). É possível, portanto, afirmar que a linguagem sempre definiu os papéis dos homens na sociedade.

Vale mencionar o posicionamento de Graff (apud MARCUSCHI, 2001; p. 23) de que o homem data de cerca de 1 milhão de anos, ao passo que a escrita só surgiu há pouco mais de 5 mil anos e a imprensa, ainda mais tardia, data de 2.500 anos, provando, assim, que a história da escrita não é só recente, como possui uma série de falhas e contradições, visto que, durante muitos anos, ficou fadada à elite e à classe religiosa, vista, portanto, como instrumento de ideologização. Seria conveniente, por essas muitas razões, considerar a oralidade e a escrita como imprescindíveis à sociedade atual, cada uma dentro do seu papel e ao seu contexto de uso. 


\title{
COERÊNCIA E COESÃO EM TEXTOS ORALIZADOS DOS PROGRAMAS DE BATE-PAPO. \\ O primeiro ponto a ser levantado é o de que a análise do sentido de
} textos de cunho oral não se dá da mesma forma que a de um texto escrito e formal. Há outros fatores que regem o processo conversacional, e é considerando esses aspectos que empreenderemos a análise.

Um estudo de Fávero (2003; p. 34) nos lembra:

\begin{abstract}
A coerência é tomada como uma possibilidade de emergência de sentido e de compreensão que se concretiza no âmbito das relações interativas entre os usuários na construção da textualidade. Pode ser caracterizada como um fenômeno complexo e de pouca evidência empírica; sua instauração no texto se dá a partir de perspectivas de produção da atividade conversacional em funcionamento. A coerência não é uma unidade de sentido, mas uma possibilidade interpretativa resultante localmente.
\end{abstract}

A coerência, de acordo com Fávero, é garantida desde que haja compreensão e entendimento do que está sendo tecido por todas as partes da interação. Como a coerência se dá dentro de uma perspectiva espacial, ou seja, entre os interlocutores no momento exato da conversação, constitui um problema encontrar marcas lexicais que assegurem a coerência tomando por base marcadores coesivos.

No entanto, as estruturas sintáticas, lexicais, bem como os marcadores conversacionais na oralidade não se dão da mesma forma que em um texto formal escrito. Há certos organizadores que serão apontados como sendo os principais responsáveis pela construção de sentido em um "texto falado", como é o caso aqui tratado, o texto de bate-papos virtuais.

Para que se dê a interação nos textos dos programas de bate-papo, os correspondentes devem estar conectados à rede da Internet e estarem na forma on line de preferência, para que os outros usuários da lista possam se comunicar, ou seja, naquele momento preciso, para receber a mensagem em tempo real. A tecnologia desses programas já avançou um pouco mais, já é 
possível o bate-papo entre duas ou mais pessoas na forma off-line, ou seja, se estiverem conectados, porém o status estiver informando que o usuário não está no ar, ainda assim é possível estabelecer contato com os outros usuários da lista, ação não possível há algum tempo.

Conforme Murray (apud HILGERT, 2001 p. 20), os enunciados produzidos nessa conversação são predominantemente lingüísticos, e cada mensagem enviada é, primeiramente, elaborada e remetida pelo comando "enviar". As mensagens podem ser recuperadas se arquivadas no comando "histórico" "salvar", ou podem se perder, as mensagens são "voláteis" se não salvas.

Na medida em que há a troca de mensagens entre emissor e receptor, em que ambos interagem entre si, começa o que é denominado de conversação na Internet, ou bate-papos, como referidos muitas vezes nesse trabalho.

A diferença que existe entre as salas de bate-papos e os programas consiste em uma mudança na forma de participação, enquanto nas salas de bate-papos, as pessoas interagem com qualquer tipo de pessoas que ali estão acessando ao mesmo tempo, nos programas há uma pré-seleção de contatos, os participantes podem adicionar contatos conhecidos de maneira prévia e não precisam adicionar aqueles que não lhes convêm.

Outra diferença básica é que nos programas as conversas são geralmente reservadas, a menos que um ou outro participante convide algumas pessoas da lista de contato para interagirem ao mesmo tempo em uma caixa de diálogo conjunta. Nas salas de bate-papos, diferentemente, primeiro há a interação em conjunto, para depois, se for conveniente, alguns participantes se convidarem para ir para uma sala reservada e interagirem sem que o grupo esteja presente.

Para que a inserção de outra pessoa se dê na conversação nos programas de bate-papo, como o Messenger do MSN, uma das partes sugere 
a inserção e a outra parte do diálogo concorda, como se dá no seguinte exemplo:

$\begin{array}{lll}\text { 15/5/2006 } & 18: 31: 43 & \text { Monena - calma, garota... } \\ 15 / 5 / 2006 & 18: 31: 56 & \text { Monena - o importante é passar de ano... } \\ 15 / 5 / 2006 & 18: 32: 14 & \text { Liskra - Coloquei a Catita para ler também } \\ 15 / 5 / 2006 & 18: 32: 22 & \text { Liskra - rsrs } \\ 15 / 5 / 2006 & 18: 32: 23 & \text { Monena - faz parte de vc não ser resumitiva... } \\ 15 / 5 / 2006 & 18: 32: 28 & \text { Monena - Cat tá online?? } \\ 15 / 5 / 2006 & 18: 32: 33 & \text { Liskra - odeio isso de resumir } \\ 15 / 5 / 2006 & 18: 32: 37 & \text { Liskra - tudo é importante } \\ 15 / 5 / 2006 & 18: 32: 49 & \text { Liskra - do contrário ela não teria explicado } \\ \text { tanto } & 18: 32: 56 & \\ 15 / 5 / 2006 & 18: 33: 03 & \text { Liskra - rsrsrsrsrs } \\ 15 / 5 / 2006 & 18: 33: 21 & \text { Catita foi adicionado(a) à conversa. } \\ 15 / 5 / 2006 & 18: 33: 38 & \text { Monena - Catita está na conversa } \\ 15 / 5 / 2006 & 18: 34: 53 & \text { Liskra - é eu vi nunca tclei c/ tres } \\ 15 / 5 / 2006 & 18: 35: 02 & \text { Monena - Holla, muchacha! } \\ 15 / 5 / 2006 & 18: 35: 06 & \text { Catita - salut mes amies! } \\ 15 / 5 / 2006 & 18: 35: 11 & \text { Monena - Alguém tem o tel. da casa da Bete?? } \\ 15 / 5 / 2006 & & \text { Catita - não... }\end{array}$

Ainda que os bate-papos sejam essencialmente escritos e próximos a textos informais como os bilhetes e cartas pessoais, eles possuem características que também se aproximam tanto da conversação telefônica como do diálogo face a face, fazendo desse gênero uma escrita peculiar, pois possuem condições de produção próprias desse meio da Internet.

\section{ORGANIZAÇÃO DA ESCRITA "FALADA" TÓPICO DISCURSIVO}

O sentido de um texto é assegurado na medida em que os tópicos conversacionais, ou aquilo do qual se está falando (BROW e YULE, 1983 apud FÁVERO, 2001; p. 38), são mantidos, ou pelo menos discorridos de forma a ser garantido um sentido, uma unidade durante a interação. Esses tópicos são uma questão de conteúdo, pois estabelecem uma relação de dependência no processo de troca de informações entre os participantes de um ato conversacional. 
Nos programas de bate-papo, o tópico discursivo muitas vezes fica comprometido quando uma das partes sugere um tema e durante 0 ato de "teclar" a mensagem a ser enviada a outra parte se manifesta com alguma outra colocação, ou algum questionamento, nem sempre dentro do tópico já sugerido anteriormente.

29/6/2006 23:24:22 (*) (\#)Minduim(\#) (*) "Extrañarte es mi necesidad, es que no te dejo de pensar."diz: Ei garotinha

29/6/2006 23:24:31 (\#) Andreia (\#)..." Because of you I never stray too far from the sidewalk..."diz: fala garota

29/6/2006 23:24:50 (*) (\#)Minduim (\#) (*) "Extrañarte es mi necesidad, es que no te dejo de pensar"diz: gostou da "gana" dos brasileiros?

29/6/2006 23:25:12 (\#) Andreia (\#)..." Because of you I never stray too far from the sidewalk..."diz: mucho

29/6/2006 23:26:03 (*) (\#)Minduim (\#) (*) "Extrañarte es mi necesidad, es que no te dejo de pensar." diz: vamos ver no que que dá

29/6/2006 23:26:15 (\#) Andreia (\#)..." Because of you I never stray too far from the sidewalk..." diz: ne menina

29/6/2006 23:26:16 (*) (\#)Minduim (\#) (*) "Extrañarte es mi necesidad, es que no te dejo de pensar" diz: está calor aí?

29/6/2006 23:26:23 (\#) Andreia (\#)..." Because of you I never stray too far from the sidewalk..." diz: ta fzendo o q acordada ate agora?

29/6/2006 23:26:28 $\quad$ (\#) Andreia (\#)..." Because of you I never stray too far from the sidewalk..."diz: muito quente

Nesse exemplo, os tópicos são mantidos até o momento em que há um desencontro de questionamentos ( $\mathrm{P}$ - está calor?/ R- ta fzendo o q acordada até agora?), pois apesar da conversa virtual se dá de forma simultânea, algumas vezes enquanto uma parte do diálogo tecla, a outra parte tecla ao mesmo tempo com um propósito diferente. O tópico é retomado assim que o texto enviado é lido por ambas as partes e uma dessas retoma o que estava ou será dito. No entanto, também ocorre de um tópico não ser de interesse de uma das partes, e, portanto, ser ignorado ou interrompido com uma nova pergunta, ou mesmo com o desvio direto de assunto a ser tratado.

Esse episódio de corte do tópico da conversação, os estudiosos de análise da conversação chamam de descontinuidade da organicidade do tópico; à quebra de um tópico com uma posterior retomada dão o nome de 
inserções e digressões, pois serão tratados de novo, só ficaram esquecidos por um intervalo de tempo.

Para que um tópico seja mantido de forma coerente e coesa é necessário, mesmo em um texto "falado", como é o caso das conversas nos programas de bate-papo, que as partes envolvidas na interação decodifiquem os elementos presentes em seus textos, de modo que as imagens, as idéias e os objetivos possam ser resgatados e desenvolvidos ao longo do intercâmbio conversacional.

Os enunciados nas conversas por messengers, por mais indecifráveis que talvez pareçam, ou que talvez seja permitido no suporte em que atuam, devem comunicar, precisam cumprir o propósito da passagem de turno para o outro, ou precisam despertar a interrupção por parte do leitor do outro lado da tela. Essa afirmação implica em um critério, dentro do mundo virtual, para os neologismos e as abreviaturas das palavras, sem querer dizer com isso, que há regras pré-estipuladas ou homogêneas, mas precisam se fazer inteligíveis.

A coerência em um texto do tipo "falado" é, de acordo com Marcuschi (2005; p. 75), uma noção relativamente híbrida, que diz respeito a uma organização de vários níveis ao mesmo tempo. Por essa razão discorremos um pouco sobre a idéia de tópicos e do desenvolvimento deles nos programas de bate-papo, mais especificamente, o Messenger.

\section{TURNOS CONVERSACIONAIS}

A condição mínima para que haja conversação é a de que os interlocutores se intercalem na qualidade de falantes e de ouvintes. Nos programas de bate-papo essa condição não é diferente, o que se distingue da conversação face a face é que a organização da mesma em turnos depende que o receptor e o emissor da interação teclem a mensagem a ser "enviada", e como isso se dá de forma escrita, ainda que seja uma ação quase que simultânea, a escrita permite com que o texto a ser enviado possa ser apagado, corrigido, retificado, diferentemente da fala. 
Por turnos se entende ser a troca, o revezamento dos participantes da ação comunicativa na categoria ora de falantes, ora de ouvintes como já foi dito anteriormente. Esses turnos podem ser simétricos, como ocorre nas conversas cotidianas em que os participantes usam a palavra da maneira que thes convier; como podem também ser assimétricos, como ocorrem quando um dos participantes detém o uso da palavra e a distribui como lhe pareça melhor .

Durante uma interação simétrica ou assimétrica, os participantes podem assumir, como fala Koch (2003; p.80), os chamados espaços de transição, esses se caracterizam por marcas como: silêncio, pausas curtas ou longas, marcas de entonação, marcas de gestos, sinais de entrega de turno, como: né?, não acha?, entendeu?, e outros.

\$13[..MaRi...] -> _ _ _ _ As coisas não são do jeito que vc pensah =//

eiii ta ouvindo? NiveR de Anne amaNhã! Quem vai?!? diz:

CaRoLiTa - Por mais q eu tente lhe dizer o qnto eu sinto por vc, como é possível não saber q eu te qru diz:

não...

\$13[..MaRi..] -> _ _ $\sim$ As coisas não são do jeito que vc pensah =//

_ N NiveR de Anne amaNhã! Quem vai?!? diz:

sua caixa de som ta ligada?

CaRoLiTa - Por mais q eu tente lhe dizer o qnto eu sinto por vc, como é possível não saber q eu te qru diz:tah

No momento em que a primeira parte do diálogo (\$13[..MaRi..] $>\sim \sim$ $\sim$ As coisas não são do jeito que vc pensah =//

NiveR de Anne amaNhã! Quem vai?!?) faz uma pergunta, automaticamente ela entrega o turno à outra parte do diálogo (CaRoLiTa - Por mais q eu tente the dizer o qnto eu sinto por vc, como é possível não saber q eu te qru), esperando que essa obedeça à regra dos pares adjacentes, nesse caso de Pergunta Resposta.

Durante as trocas de turnos podem ocorrer várias situações, por exemplo, a tomada de turno. Quando um participante que não foi convidado a se expressar sobrepõe quem está falando no momento, se diz que houve um 
assalto de turno, até que um ou outro entregue o turno há uma sobreposição de informações nem sempre encontradas.

O que constatamos nas conversas virtuais é que o assalto do turno se dá apenas se uma das partes do diálogo muda repentinamente do assunto de que estava tratando, pois para haver um próximo turno as partes da conversação devem teclar suas informações e posteriormente enviam para o seu receptor, ou seja, para teclarem algo, devem estar atentos ao assunto que circunda a conversa eletrônica.

$\begin{array}{lr}\text { 03/06/2006 } & 17: 06: 26 \\ \text { 03/06/2006 } & 17: 06: 35 \\ \text { show/clips do slipknot } \\ \text { 03/06/2006 } & 17: 07: 33 \\ \text { manha o PC. } & \\ \text { 03/06/2006 } & 17: 07: 39 \\ \text { 03/06/2006 } & 17: 07: 51 \\ \text { 03/06/2006 } & 17 ; 08: 04 \\ \text { 03/06/2006 } & 17: 08: 21 \\ \text { 03/06/2006 } & 17: 08: 23 \\ \text { windows? } & \\ \text { 03/06/2006 } & 17: 08: 30 \\ \text { 03/06/2006 } & 17: 09: 07 \\ \text { instalei } & \\ \text { 03/06/2006 } & 17: 09: 09 \\ \text { 03/06/2006 } & 17: 09: 12 \\ \text { 03/06/2006 } & 17: 09: 22\end{array}$

Rober diz: fazendu uq? $\hat{A}^{\circ} \sim_{-}^{*} \tilde{A} \ldots . . k \tilde{A} \ltimes a ̂ € \hat{A} \mu^{*} \sim \hat{A}^{\circ}$ diz: assistindu $\hat{A}^{\circ} \sim_{-}^{*} \tilde{A} \ldots k \tilde{A}$ â€€ Â$\mu^{*} \sim \hat{A}^{\circ}$ diz: fomatei hj de Rober diz: $\mathbf{c}$ ta com o cd do windows xp ai??! $\hat{A}^{\circ} \sim{ }^{*} \tilde{A} \ldots . . . k \tilde{a} a \hat{a} € \hat{A} \mu^{*} \_\sim \hat{A}^{\circ} \operatorname{diz:} \operatorname{sim}$ $\hat{A}^{\circ} \sim_{-}^{-} \tilde{A} . . . k \tilde{A} q a ̂ € \hat{A} \mu^{*}{ }_{-} \sim \hat{A}^{0}$ diz: eh meu Rober diz: com ele da pra instalar. $\hat{A}^{\circ} \sim_{-}^{*} \tilde{A} \ldots k \tilde{A} \not a ̂ € \hat{A} \mu^{*} \sim \hat{A}^{\circ}$ diz: instalar o $\hat{A}^{\circ} \sim{ }^{*} \tilde{A} . . . k \tilde{A}$ qâ€ $\hat{A} \mu^{*} \sim \hat{A}^{0}$ diz: claro $\hat{A}^{o} \sim_{-}^{-} \tilde{A} \tilde{A} . . k \tilde{A}$ qâ $€ \hat{A} \mu^{*}{ }_{-} \sim \hat{A}^{\circ}$ diz: hj eu formatei e Rober diz: q massa Rober diz: pod me emprestar? $\hat{A}^{\circ} \sim{ }_{-}^{*} \tilde{A} \ldots k \tilde{A}$ â $€ \hat{A} \mu^{*} \_\sim \hat{A}^{\circ} \operatorname{diz}: \operatorname{sim}$

O início do bate-papo, depois dos cumprimentos, foi introduzido por uma pergunta que exigiu a resposta da parte do receptor - fazendu uq?; assistindu show/clips do slipknot- como o receptor da pergunta pegou o turno, redirecionou a conversa para o assunto que melhor the convinha naquele momento, que era o da formatação do seu computador. Respeitando as regras conversacionais, a outra parte do diálogo de ouvinte passa a ser o falante, mas dentro do proposto pelo turno posterior ao seu, visto que também the interessava o assunto como pôde ser notado pelo avanço dos turnos no mesmo assunto. 
Os recursos que permitem ao falante sustentar, segurar o turno são habitualmente marcadores de busca de aprovação discursiva: entende?, né?, não acha?; repetições; alongamento de assunto. Como no exemplo:

Leandro...FALTAM 8 DIAS PARA O FESTIVAL DE ALEGRE! !!!!! diz: 0 palco já ta montadinho

déBorA diz: tb, ta mto perto né?!

Leandro...FALTAM 8 DIAS PARA O FESTIVAL DE ALEGRE!!!!!! diz: Já estão começando a montar os camarotes.

déBorA diz: e acredite se quiser, Rafaela vaaaaaaaaai

Leandro...FALTAM 8 DIAS PARA O FESTIVAL DE ALEGRE! !!!!! diz: vão começar a enfeitar já jpa

Leandro...FALTAM 8 DIAS PARA O FESTIVAL DE ALEGRE! !!!!! diz: sabia ué

déBorA diz: hehehehehe sovou acreditar qdo a gente tiver no bus!

Leandro...FALTAM 8 DIAS PARA O FESTIVAL DE ALEGRE! ! !!! ! diz: já tava certo

déBorA diz: tava nada, ela falou com leninha esses dias atrás ai

déBorA diz: ela comprou todo sem falar com leninha

É possível se manter o tópico conversacional mesmo por meio de turnos inseridos, ou seja, conteúdos inseridos na conversação sem caráter referencial.

O dinamismo é um caráter marcante da conversação, como se pôde observar nesse breve esboço sobre os turnos conversacionais. Vários foram os traços apontados para que fosse percebido esse dinamismo, como: a troca de posição entre os interlocutores, na posição de falantes e ouvintes; o monitoramento da fala do outro interlocutor, com turnos inseridos sem caráter referencial; o assalto ao turno e a sustentação do turno.

Para que esses traços ocorram de fato na conversação, é necessário o uso de marcadores conversacionais. Como mostrado nesse artigo anteriormente, na conversação virtual, são constantes os marcadores paralingüísticos e os metalingüísticos, que merecem atenção na análise dos bate- papos via Internet.

Os marcadores paralingüísticos e metalingüísticos, segundo Marcuschi (2005a; p.23), são organizadores conversacionais, uma vez que "as falas simultâneas e as sobreposições de vozes [ou de textos] são momentos cruciais 
na organização conversacional, pois nesses momentos o sistema pode entrar em colapso".

Os marcadores paralingüísticos atuam nos bate-papos na Internet como ícones que reproduzem gestos humanos, como um olhar incisivo, um movimento com as mãos. Steinberg (apud DIONÍSIO, 2003; p. 77) diz que os elementos paralingüísticos atuam como uma espécie de modificadores do aparelho fonador, ou a completa ausência de atividade desse aparelho, incluindo nessa esfera todos os sons e ruídos não-lingüísticos, como assobios e sons onomatopaicos.

$\mathrm{Na}$ conversação da Internet esses elementos são bem visíveis com a presença dos emoticons e dos winks, além de outros elementos, como a reprodução gráfica de sons e ruídos onomatopaicos:

$\begin{array}{lll}16 / 04 / 2005 & 19: 02: 48 & \text { Silveira }- \text { oi } \\ \text { 16/04/2005 } & 19: 03: 01 & \text { LeNa }- \text { uhauahuahuahuah oioi } \\ \text { 16/04/2005 } & 19: 03: 03 & \text { LeNa }- \text { td bom? } \\ \text { 16/04/2005 } & 19: 03: 15 & \text { Silveira }- \text { tudo e vc??? } \\ \text { 16/04/2005 } & 19: 03: 36 & \text { LeNa }- \text { tbn } \\ \text { 16/04/2005 } & 19: 03: 38 & \text { LeNa }-\underline{\text { HGUh }} \\ 16 / 04 / 2005 & 19: 03: 45 & \text { Silveira }-\underline{3}\end{array}$

Os marcadores paralingüísticos ainda são subdivididos conforme as funções que exercem no contexto conversacional, podem ser classificados como lexicais, quando temos algum episódio não-lingüístico para indicar alguma palavra ou expressão, e o descritivo, que suplementa o significado da troca conversacional por meio de ícones que substituem os gestos dos olhos, da boca, das mãos.

Podemos concluir, que mesmo sem a presença real nos bate-papos pela Internet, é possível "falarmos" com a voz e com o corpo, já que se utilizam muitas entradas a fim de suprir a presença face a face de uma conversa real.

Os marcadores metalingüísticos são uma espécie de norma que rege a boa condução do evento conversacional. 
$\mathrm{Na}$ interação virtual, esses marcadores também estão presentes e são muito utilizados principalmente para marcar a ausência na conversa de um dos usuários por alguns instantes, uma vez que a interação não se dá face a face, os marcadores metalingüísticos atuam em auxílio dos participantes da conversa virtual, a fim de que não haja uma quebra de trocas de informações e comprometa a conversação.

déBorA... diz: ela $\mathbf{n}$ aceita mto bem!!!!! alias, o ser humano $\mathbf{n}$ aceita mto bem criticas né?

é assim com tdo mundo

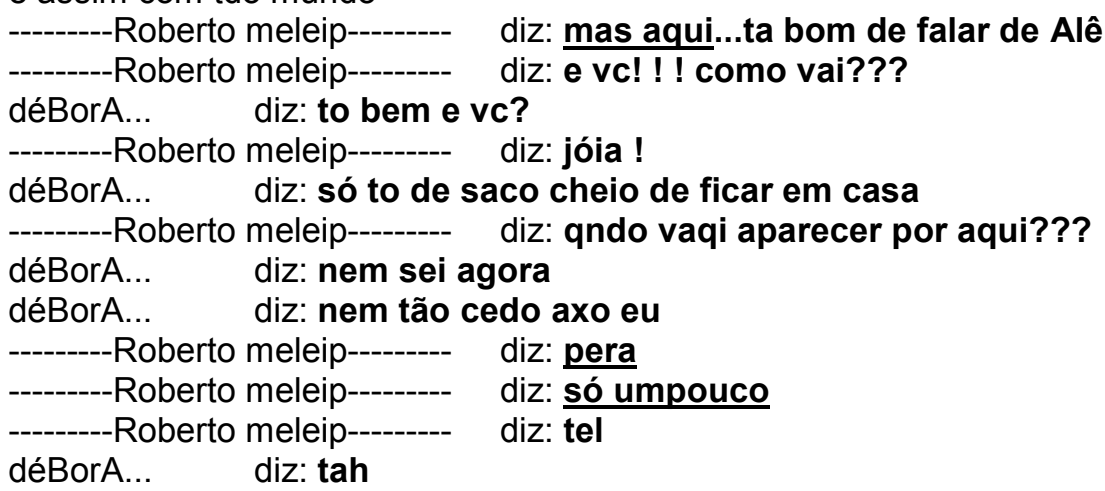

O texto sublinhado mostra algumas formas de os marcadores metalingüísticos servirem de auxilio na conversação virtual. Elementos como: peraí, ei...vamos mudar de assunto, ah tah, vo dar uma saidinha, já volto, organizam a conversação, além de localizarem os interlocutores com relação a desaprovação do conteúdo que está sendo tratado, a ausência durante a conversa por motivos de várias naturezas, como mostrado no exemplo, um telefonema, é motivo para uma saída da conversa.

Nos programas de bate-papo outros fatores organizam a conversação como tamanho da letra (fonte) utilizada, cor da fonte, letras maiúsculas ou minúsculas. Mediante a análise dos textos de programas de bate-papo foi possível caracterizar o uso de letras maiúsculas como um recurso para expressar ênfase no que se quer dizer, e outro ponto observado também é que o uso desse recurso gráfico é mais utilizado por adolescentes entre $13-18$ 
anos. Ao contrário do que se imaginava há algum tempo, o texto das conversas virtuais só pode ser compreendido devido à atividade intencional por parte dos interlocutores de formularem textos que ofereçam marcas para que sejam compreendidos. Essa tarefa é que torna a conversação ao mesmo tempo uma atividade de ação e interação.

Quanto à linguagem não-padrão empregada, cheia de neologismos e abreviaturas, também é peculiar ao suporte utilizado e que só causa uma estranheza à primeira vista, pois essa é logo desfeita quando começa a interação e a captação do que exige o meio.

A fala está dentro do plano do continuum da língua em um pólo diferente do que está a escrita, ainda que os dois fatores da língua não estejam, nesse trabalho, sendo tratados de forma dicotômica e com privilégios, no pólo da fala há textos que são próprios da fala, como é o caso de bilhetes, recados e as conversações dos programas de bate-papo. Enquanto que no pólo da escrita há uma vastidão de textos que obedecem a critérios bem delimitados para textos escritos.

No caso das conversações via Internet, elas possuem um caráter híbrido, considerando a fala e a escrita, por essa razão temos regras maleáveis, para que não comprometam o estabelecimento do sentido no texto. Não podemos esperar que a coerência e a coesão de textos falados se dêem da mesma forma que nos textos escritos formais, uma vez que se espera de uma conversação formas mais dinâmicas e menos formuladas.

\section{Referências Bibliográficas}

DIONíSIO, Ângela Paiva. Análise da conversação. In:MUSSALIM, Fernanda; BENTES, Anna Christina Bentes (orgs). Introdução à lingüística: domínios e fronteiras, v. 2. $3^{\text {a }}$ ed. São Paulo: Cortez, 2003. 
FÁVERO, Leonor Lopes; ANDRADE, Maria Lúcia C. V. O.; AQUINO, Zilda G.

O. Oralidade e escrita-perspectivas para o ensino de língua portuguesa. 4. ed. São Paulo: Cortez, 2003.

FÁVERO, Leonor Lopes. O tópico discursivo. In: PRETTI, Dino (org.). Análise de textos orais. 5 ed. São Paulo: Humanitas FFLCH/ USP, 2001. (PROJETOS PARALELOS: V. I), p.33-54

HILGERT, José Gaston. A construção do texto "falado" por escrito: conversação na Internet. In: PRETTI, Dino (org.). Fala e escrita em questão. 2 ed. São Paulo: Humanitas, 2001, p. 17-55.

$\mathrm{KOCH}$, Ingedore Villaça. A inter-ação pela linguagem. 8.ed. São Paulo: Contexto, 2003.

MARCUSCHI, Luís Antônio. Gêneros textuais: definição e funcionalidade. In: DIONISIO, Ângela Paiva; MACHADO, Anna Rachel; BEZERRA, Maria Auxiliadora. (org.). Gêneros textuais \& ensino. 2. ed. Rio de Janeiro: Lucerna, 2003.

MARCUSCHI, Luiz Antônio. Análise da conversação. 5. ed. São Paulo: Ática, $2005 a$.

. Produção textual, análise de gêneros e compreensão. 3 versão.

Recife: Departamento de Letras, UFPE, 2005.

MARCUSCHI, Luiz Antônio; XAVIER, Antonio Carlos (org.). Hipertexto

e_gêneros_digitais. Rio de Janeiro: Lucerna, 2004.

OLSON, David R. O mundo no papel : as implicações conceituais e cognitivas da leitura e da escrita. São Paulo: Ática, 1997. 